\title{
Genetic Evaluation of Fertility Using Direct and Correlated Traits
}

\author{
E. Wall, ${ }^{*}$ S. Brotherstone, ${ }^{\star} \dagger$ J. A. Woolliams, $\neq$ \\ G. Banos,§ and M. P. Coffey* \\ *Sustainable Livestock Systems Group, \\ Scottish Agricultural College, \\ Bush Estate, Penicuik, Midlothian, EH26 OPH U.K. \\ †Institute of Cell, Animal and Population Biology, \\ University of Edinburgh, Ashworth Laboratories, \\ King's Buildings, Edinburgh, EH9 3JT U.K. \\ ‡Roslin Institute (Edinburgh), Roslin, Midlothian, EH25 9PS U.K. \\ $\S$ Faculty of Veterinary Medicine, Aristotle University, \\ GR-54124 Thessaloniki, Greece
}

\section{ABSTRACT}

Poor fertility has become a major reason for involuntary culling of dairy cows in the United Kingdom. Calving interval (CI) and body condition score (BCS) are recorded, heritable, genetically correlated with each other, and could be used to extend the scope of dairy indices to include fertility traits. The use of U.K. insemination information for the evaluation of fertility has not been examined previously. Fertility and correlated traits were examined using nationally recorded milk (MILK = daily milk yield at test nearest d 110), BSC, and fertility traits (CI and the insemination traits of nonreturn rate after $56 \mathrm{~d}$, NR56; days to first service, DFS; and number of inseminations per conception, INS). Genetic parameters for the traits were estimated simultaneously with a multitrait sire maternal grandsire (MGS) model and a multitrait BLUP sire MGS model was used to predict sire predicted transmitting abilities for each trait. The relationship between the fertility traits and other predicted transmitting abilities calculated in the United Kingdom was then examined. Heritabilities for the fertility traits were CI = $0.033 \pm 0.01, \mathrm{DFS}=0.037 \pm 0.01, \mathrm{NR} 56=0.018 \pm 0.001$, and INS $=0.020 \pm 0.001$, with a genetic correlation of $0.671 \pm 0.063$ between CI and DFS and $-0.939 \pm 0.031$ between NR5 6 and INS. There was an unfavorable genetic correlation between the fertility traits and milk yield and BCS. Predicted transmitting abilities produced are similar in size and range to those produced in other studies and genetic trends are as expected. Results to date are encouraging and suggest that the planned program of work will lead to a fertility index that, when used by breeding companies, will lead to improvements in national dairy cow fertility.

Received May 23, 2003

Accepted August 13, 2003.

Corresponding author: E. Wall; e-mail: e.wall@ed.sac.ac.uk.
(Key words: calving interval, fertility, insemination information)

Abbreviation key: $\mathbf{C I}=$ calving interval, $\mathbf{N R 5 6}=$ nonreturn rate after $56 \mathrm{~d}$, DFS = days to first service, INS = number of inseminations per conception, MILK = daily milk yield at d 110, MILK 305 = kilograms of milk over a 305-d lactation, FAT = kilograms of fat over a 305-d lactation, PROT $=$ kilograms of protein over a 305-d lactation, $\mathbf{L S}=$ lifespan PTA, $\mathbf{E P L I}=$ profitable lifetime index, $\mathfrak{e P I N}=$ production index .

\section{INTRODUCTION}

The correlation between fertility and production is generally unfavorable in dairy cows (e.g., Pryce et al., 1997, 1998; Pryce and Veerkamp, 2001). Consequently, in the absence of any direct selection pressure on fertility, there has been a downward genetic trend in fertility associated with selection for yield (e.g., Royal et al., 2000). Poor on-farm fertility can be partially addressed by management changes (improved feeding, better heat detection, etc.). These require continuous inputs and therefore attract continuous costs, suggesting that this route to improved fertility is unsustainable in the long term. Ignoring the genetic component of poor fertility masks the severity of the problem, and a failure to tackle the genetic component of the problem is expected to lead to a continuing downward genetic trend. Genetic selection may provide a cost-effective, cumulative, and permanent method for improvement of fertility in the national U.K. dairy herd.

Ideally, female fertility indices include 1 or both of the following types of measurement: 1) a measure of conception success following insemination, and 2) reproductive rate measured by intervals, such as calving interval (CI). The heritabilities of these aspects of reproductive performance are low (typically $<0.05$ ); consequently, the reliability of bull evaluations for fertility is generally lower than other traits, such as milk pro- 
duction, when estimated from the same number of daughters. Information on the fertility of milking heifers is of particular interest because it is available when important decisions on progeny test bulls are made.

Even though direct recording of fertility in national milk recording schemes is generally more open to measurement error and is less widespread, fertility traits are genetically correlated with traits that are either well recorded or more heritable, such as yield (for a review, see Pryce and Veerkamp, 2001), condition score (Pryce et al., 2000), BW (Berry et al., 2003), and linear type traits (Harrison et al., 1990). As a result, direct measures of fertility (calving interval, insemination data) and records on correlated traits, such as yield and condition score, can be used to supplement the predictions of genetic merit for fertility. The use of yield and condition score is beneficial because they can help overcome management biases that may be present in the fertility data. The correlation between milk yield and fertility is not one, therefore a favorable selection response in fertility can be achieved while still achieving gains in milk production. However, there are costs in loss of progress in milk production (Veerkamp et al., 2000). This suggests that milk yield and fertility traits need to be optimized within an overall economic index.

Calving interval has a relatively high economic weight (Groen et al., 1997), and a reduction in CI could be described as one of the outcomes of improved fertility. However, CI requires a record of consecutive calving dates and is therefore only available after a second calving. Relying on CI alone would delay selection decisions on young test bulls. Furthermore, CI is open to management bias (e.g., decisions to extend the lactation length of individual high-yielding cows within herds). Early measures on components of CI can be useful in overcoming some of these problems. For example, days to first service (DFS) are available much earlier and have been shown to be heritable (de Jong, 1997; Evans et al., 2002) and strongly correlated to CI (de Jong, 1997).

Kadarmideen and Coffey (2001), in an analysis of U.K. insemination data, showed that only about $10 \%$ of herds that participate in herd milk recording had all the expected service dates, and over $15 \%$ of herds failed to record almost all services. Missing records occur for different reasons (e.g., inseminations not being recorded by the producer or the producer failing to report all successful or unsuccessful services to milk recorders). Because of these characteristics of insemination data, careful editing is required before insemination data can be used to derive fertility proofs (Kadarmideen and Coffey, 2001).

A further use of insemination data is the derivation of the pregnancy status of a cow $56 \mathrm{~d}$ after first insemi- nation, commonly known as nonreturn rate at d 56 (NR56). This trait reflects the ability of a cow to maintain a pregnancy over the period of early gestation. Nonreturn rate at d 56 is internationally recommended and widely used (Groen, 1999), and is an important trait for allowing international comparisons. The number of inseminations required to produce a calving (INS) is closely related to the goal of improving fertility and has a clear economic interpretation. It suffers from the same limitations as CI, in that it is necessary to have a second calving and it relies on consistent recording, as all inseminations need to be recorded.

The objective of this study was to develop the framework necessary for a national fertility index using records on fertility and the correlated traits of yield and BCS. This required 1) estimation of the necessary genetic parameters for fertility, yield, and BCS, 2) development of statistical models for producing sire PTA for these traits, and 3) examination of the relationship between these and other functional and production PTA.

\section{MATERIALS AND METHODS}

\section{Available Data}

A number of direct fertility traits were defined using information on inseminations and calvings from national milk recording databases, including: 1) CI, 2) DFS, 3) INS, and 4) a binary trait measuring NR56. The rules used to validate fertility traits that relied on insemination information (DFS, INS, NR56) are given in the Appendix.

Previous analyses have shown that correlations of different yield traits (e.g., 305-d yield, milk fat or milk protein yield, individual test yields) with CI were all unfavorable and did not statistically differ from each other (Brotherstone et al., 2002). The yield trait chosen was daily yield of milk at the test nearest to $\mathrm{d} 110$ (MILK) because this is close to the average day when cows become pregnant and approximates the minimum of 3 tests required for including heifer records in production evaluations. Body condition score is genetically unfavorably correlated with CI (Pryce et al., 2000). Body condition score observed during the first lactation was chosen and was recorded in the field on a scale of 1 to 9 , where $1=$ thin and $9=$ fat, for animals participating in the type classification scheme operated by Holstein U.K. This score was adjusted for recording officer by scaling records so that individual field officer standard deviations were equal to the mean standard deviation of all field officers (Jones et al., 1999). 


\section{Genetic Parameter Estimation}

Insemination, calving, BCS, and milk yield records of first-parity Holstein cows were extracted from the databases of National Milk Records plc and Holstein U.K. All cows had calved between 1997 and 2000 and were required to have complete 305 -d lactation yield records with at least 7 tests included. Lactation records were excluded if 1 of the following occurred 1) age at calving was outside the range of 18 to $36 \mathrm{mo}, 2$ ) daily milk yield was less than $5 \mathrm{~kg}$ or greater than $60 \mathrm{~kg}$, 3) milk yield was less than $1000 \mathrm{~kg}$ for the complete lactation, 4) the date of BCS was more than $20 \mathrm{~d}$ from the date of a milk record, 5) CI was outside the range of 300 to $600 \mathrm{~d}$, and 6) first insemination was before d 20 or the last insemination was after d 200. Further, herd-year combinations were required to have a minimum of 5 observations and sires had to have at least 10 daughters. After these edits, there were 43,029 cow records in 7029 herd-year subclasses from 1390 sires; $75 \%$ of the cow records had CI and 30\% had BCS.

The data were analyzed with REML analyses to estimate the variance components using VCE4 (Neumaier and Groeneveld, 1998). Hexavariate analyses were run for CI, BCS, MILK, DFS, NR56, and INS. A linear model was fitted that included sire as a random effect. The sire's sire and his maternal grandsire were specified in a truncated pedigree file:

$$
\begin{aligned}
& \mathbf{P}_{i j k}=\mu+\mathrm{hs}_{i}+\operatorname{month}_{j}+\beta_{1} \mathbf{X}_{\text {age }}+\beta_{2}\left(\mathbf{X}_{\text {age }}\right)^{2}+\operatorname{sire}_{k}+\mathrm{e}_{i j k} \\
& \mathrm{~T}_{i j k}=\mu+\mathrm{hs}_{i}+\operatorname{month}_{j}+\beta_{1} \mathrm{X}_{\mathrm{age}}+\beta_{2}\left(\mathrm{X}_{\mathrm{age}}\right)^{2}+\beta_{1} \mathrm{X}_{\mathrm{DIM} \_\mathrm{T}} \\
& +\beta_{2}\left(\mathrm{X}_{\mathrm{DIM} \_\mathrm{T}}\right)^{2}+\operatorname{sire}_{k}+\mathrm{e}_{i j k} \\
& \mathrm{~V}_{i j k}=\mu+\mathrm{hsc}_{i}+\operatorname{month}_{j}+\beta_{1} \mathrm{X}_{\mathrm{age}}+\beta_{2}\left(\mathrm{X}_{\mathrm{age}}\right)^{2}+\beta_{1} \mathrm{X}_{\mathrm{DIM} \_\mathrm{C}} \\
& +\beta_{2}\left(\mathrm{X}_{\mathrm{DIM}_{-} \mathrm{C}}\right)^{2}+\operatorname{sire}_{k}+\mathrm{e}_{i j k},
\end{aligned}
$$

where $\mathrm{P}_{i j k}=\mathrm{CI}$, DFS, NR56, or INS; $\mathrm{T}_{i j k}=$ MILK; $\mathrm{V}_{i j k}$ $=\mathrm{BCS} ; \mathrm{hs}_{\mathrm{i}}=$ fixed effect of $i$ th herd $\times$ year of calving interaction; hsc $_{i}=$ fixed effect of $i$ th herd $\times$ year of visit interaction on BCS; month $_{j}=$ fixed effect of the $j$ th month of calving; $\beta_{1}$ and $\beta_{2}=$ linear and quadratic regression coefficients of dependent variable $(\mathrm{P}, \mathrm{T}$, or $\mathrm{V})$ on age effect or days in milk at test effect; $\mathrm{X}_{\text {age }}=$ continuous variable representing age of animal at calving; $\mathrm{X}_{\mathrm{DIM} \_\mathrm{T}}=$ continuous variable representing days in milk at test; $\mathrm{X}_{\text {DIM_C }}=$ continuous variable representing days in milk at BCS measurement visit; sire $_{k}=$ the random genetic effect of sire $k$; and $\mathrm{e}_{i j k}=$ residual random error term.

\section{Predicted Transmitting Ability Estimation}

Data for the multivariate genetic analysis of bulls for the fertility traits were extracted from the Cattle
Information Services, National Milk Records, and Holstein U.K. databases. Records for first-lactation animals with at least 3 tests were taken from 1992 until the end of 2002 because individual test-day records were only available for all animals from 1992. Lactation records were excluded if they failed to meet 1 of the following criteria: 1) age at first calving was between 18 and $40 \mathrm{mo}, 2)$ a test-day record was available between d 80 and 140 of lactation (for MILK at $110 \mathrm{~d}$ ), with milk yield between 5 and $60 \mathrm{~kg}, 3$ ) if a second calving occurred, the calving interval was between 300 and 600 $\mathrm{d}, 4)$ if insemination information was present, the first insemination was recorded by d 200, and 5) BCS was recorded by d 400 of lactation. Animals with more than 10 inseminations were removed.

A total of 1,828,389 first-lactation records remained after editing. Over $68 \%$ of cows had a CI, over $13 \%$ had BCS information, and $89 \%$ had at least one insemination record, with $65 \%$ having a record for INS. There was a total of 27,718 sires with daughters in the dataset and over 50,000 animals in the pedigree file. Genetic groups were fitted for all unknown parents, using 24 genetic groups. Assignment to genetic groups was based upon sex, year of birth, breed (Holstein separate from Friesian), and country of origin for Holsteins (e.g., Canada or United States). If the number of animals in each group was low (less than 20), similar genetic groups were combined.

Multitrait BLUP PTA were estimated using the PEST program (Groeneveld et al., 1990) fitting a sire maternal-grandsire model and using genetic parameters obtained as described above. The full linear model differed slightly from that used for parameter estimation, with herd $\times$ year $\times$ season replacing herd $\times$ year interaction. Each PTA was adjusted by subtracting a base value equal to the average PTA of those Holstein bulls born between 1984 and 1993 that had a reliability of $30 \%$ or more for CI. This genetic base is analogous to that used for type proofs in the United Kingdom.

\section{Genetic Relationships Between Fertility and Other Traits}

Correlations of the PTA of the fertility traits with other available PTA were calculated. The latter included PTA for 305-d yields of milk (MILK 305), fat (FAT), and protein (PROT), lifespan (LS), and SCC. Lifespan is estimated directly from completed lactation information and indirectly from type traits (Brotherstone et al., 1997). Somatic cell count PTA are produced using an animal model and information from the first 3 lactations (Mrode et al., 1998). Correlations of the PTA for fertility with 2 economic indices were also calculated: an economic index for production (£PIN) 
Table 1. Mean, SD, and $\mathrm{h}^{2}$ for calving interval (CI), BCS, kilograms of milk at d 110 (MILK), days to first service (DFS), nonreturn rate (NR56), and the number of inseminations per conception (INS).

\begin{tabular}{llrrl}
\hline Trait & No. recs. & Mean & \multicolumn{1}{l}{ SD } & \multicolumn{1}{l}{$\mathrm{h}^{2}$} \\
\hline CI (days) & 32,205 & 387.94 & 50.50 & $0.033 \pm 0.001$ \\
BCS (score) & 12,866 & 4.45 & 1.72 & $0.237 \pm 0.008$ \\
MILK (kg) & 43,029 & 23.64 & 5.39 & $0.329 \pm 0.003$ \\
DFS (days) & 43,029 & 81.61 & 30.01 & $0.035 \pm 0.001$ \\
NR56 (0/1) & 42,995 & 0.65 & 0.48 & $0.018 \pm 0.001$ \\
INS (count) & 32,209 & 1.67 & 1.00 & $0.020 \pm 0.002$ \\
\hline
\end{tabular}

${ }^{1} \mathrm{~A} 0$ indicates a return to service, 1 indicates no return to service.

combining MILK 305, FAT, PROT, and an economic index for profitable life (£PLI), combining £PIN and LS. The PTA for each pair of traits had to have a reliability of at least $80 \%$ for inclusion in the calculation of correlations.

Genetic correlations were estimated from the correlations between the PTA and the reliability of the PTA (Hickman et al., 1969; Calo et al., 1973):

$$
\hat{r}_{g 1,2}=\frac{\sqrt{\Sigma R E L_{1} \times \Sigma R E L_{2}}}{\Sigma\left(R E L_{1} \times R E L_{2}\right)} \times r_{1,2},
$$

where $R E L_{1}$ and $R E L_{2}=$ reliabilities of the PTA of trait 1 (the fertility trait analysis, CI, DFS, NR56, INS, BCS, MILK) and trait 2 (other traits, MILK 305, FAT, PROT, LS, SCC, £PIN, £PLI), and $r_{1,2}=$ correlation between the PTA for traits 1 and 2.

\section{RESULTS}

\section{Genetic Parameter Estimation}

Table 1 provides a summary of the data and descriptive statistics of all traits in the dataset used for parameter estimation. The average CI was $388 \mathrm{~d}$, the average number of recorded services per conception was 1.66 , and results showed that $65 \%$ of the cows did not return to service within $56 \mathrm{~d}$. Heritability estimates were low for all fertility traits $(\mathrm{CI}=0.033$, DFS $=0.037$, NR56 = $0.018, \mathrm{INS}=0.020)$ and moderate for $\operatorname{MILK}(0.329)$ and
BCS (0.237). Heritability estimates for CI, BCS, INS, and NR56 were similar to earlier estimates in the United Kingdom (Pryce et al., 2000; Kadarmideen et al., 2000) and elsewhere (Veerkamp et al., 2001).

The correlations of CI with DFS and INS were strong and favorable (Table 2) and were of a magnitude similar to other studies (de Jong, 1997), suggesting that improving 1 fertility trait would result in a correlated improvement in other fertility traits. These results suggest that a longer CI is linked to more recorded inseminations and a longer time for the cow to return to estrus after calving. The correlations between DFS and conception rate traits (NR56 and INS) were not significantly different from zero but are of a similar magnitude to those reported by other studies (Roxström et al., 2001).

The correlation of BCS with DFS and CI was positive and agreed with other studies (Dechow et al., 2001; Veerkamp et al., 2001), indicating that increased BCS is associated with shorter DFS and therefore shorter CI. The correlation of MILK with CI was moderately unfavorable (0.27), suggesting that increased milk production is associated with longer CI, confirming the results of earlier studies (e.g., Kadarmideen et al., 2000). In this study, selection bias due to milk production is, at least partially, accounted for by the inclusion of MILK in the multiple-trait analysis, since at least some of the data on which selection had been based were included. Genetic correlation estimates between MILK and INS and NR56 were not significantly differ-

Table 2. Estimates of genetic SD (diagonal), genetic correlations (above diagonal), and residual correlations (below diagonal) for CI, BCS, MILK, DFS, NR56, and INS. ${ }^{1}$

\begin{tabular}{|c|c|c|c|c|c|c|}
\hline Trait & CI & BCS & MILK & DFS & NR56 & INS \\
\hline CI & 8.95 & $-0.14 \pm 0.099$ & $0.27 \pm 0.051$ & $0.67 \pm 0.063$ & $-0.45 \pm 0.075$ & $0.61 \pm 0.058$ \\
\hline BCS & $-0.06 \pm 0.004$ & 0.68 & $-0.44 \pm 0.027$ & $-0.63 \pm 0.078$ & $-0.30 \pm 0.097$ & $0.29 \pm 0.095$ \\
\hline MILK & $0.05 \pm 0.003$ & $-0.16 \pm 0.003$ & 2.34 & $0.49 \pm 0.049$ & $-0.25 \pm 0.071$ & $0.06 \pm 0.064$ \\
\hline DFS & $0.48 \pm 0.002$ & $-0.08 \pm 0.002$ & $0.04 \pm 0.003$ & 5.03 & $0.24 \pm 0.114$ & $-0.12 \pm 0.118$ \\
\hline $\mathrm{NR}^{2} 6^{2}$ & $-0.34 \pm 0.003$ & $0.01 \pm 0.002$ & $-0.03 \pm 0.002$ & $0.02 \pm 0.003$ & 0.06 & $-0.94 \pm 0.031$ \\
\hline INS & $0.67 \pm 0.002$ & $-0.01 \pm 0.002$ & $0.04 \pm 0.003$ & $-0.06 \pm 0.003$ & $-0.68 \pm 0.002$ & 0.14 \\
\hline
\end{tabular}

${ }^{1}$ For definitions, see Table 1.

${ }^{2} \mathrm{~A} 0$ indicates a return to service, 1 indicates no return to service. 
Table 3. Mean, SD, and range of sire PTA estimated from a multitrait BLUP evaluation.

\begin{tabular}{lrrrrrr}
\hline & \multicolumn{1}{c}{ CI } & \multicolumn{1}{c}{ BCS } & MILK & DFS & NR56 & INS \\
\hline Mean & 0.04 & -0.01 & 0.04 & 0.04 & 0.00 & 0.01 \\
Standard deviation & 2.98 & 0.26 & 1.26 & 1.92 & 0.02 & 0.04 \\
Interquartile range & 3.88 & 0.32 & 1.71 & 2.52 & 0.02 & 0.05 \\
Minimum & -12.73 & -1.12 & -5.21 & -7.06 & -0.07 & -0.15 \\
Maximum & 16.54 & 1.23 & 4.06 & 9.10 & 0.07 & 0.16 \\
\hline
\end{tabular}

ent from zero, whereas correlations with DFS were unfavorable, with higher yield being associated with increased time to first insemination. The correlation between BCS and MILK was also unfavorable.

\section{Predicted Transmitting Ability Estimation}

The mean, standard deviation, and range of sire PTA for the 6 traits are presented in Table 3, with distributions of PTA shown in Figure 1. The sire PTA for CI fall within the range of those seen in other studies (e.g., Olori et al., 2002) with $95 \%$ of bulls lying in a $10-d$ range ( -5 to $5 \mathrm{~d}$ ). The full range of PTA for the interval trait DFS was $16 \mathrm{~d}$, but $95 \%$ of bulls had PTA in a 7 - d range (-3 to $4 \mathrm{~d}$ ). The range of PTA for NR56 appears to be narrow (0.14) but is biologically significant when describing a binary trait. The range of INS PTA is quite wide ( 0.3 of an insemination), especially when the average number of inseminations in this dataset was 1.66.

There is a high correlation between the PTA of BCS with CI, MILK, and DFS $(-0.45,-0.62$, and -0.72 , respectively), and there is also a strong correlation $(>0.9)$ between the PTA for INS and NR56. The correlations between the PTA are similar in magnitude to the genetic correlations used to estimate the PTA. There is an unfavorable trend in all the fertility traits, particularly in more recent years (see Figure 2). The interval traits (CI and DFS) have increased over time, resulting
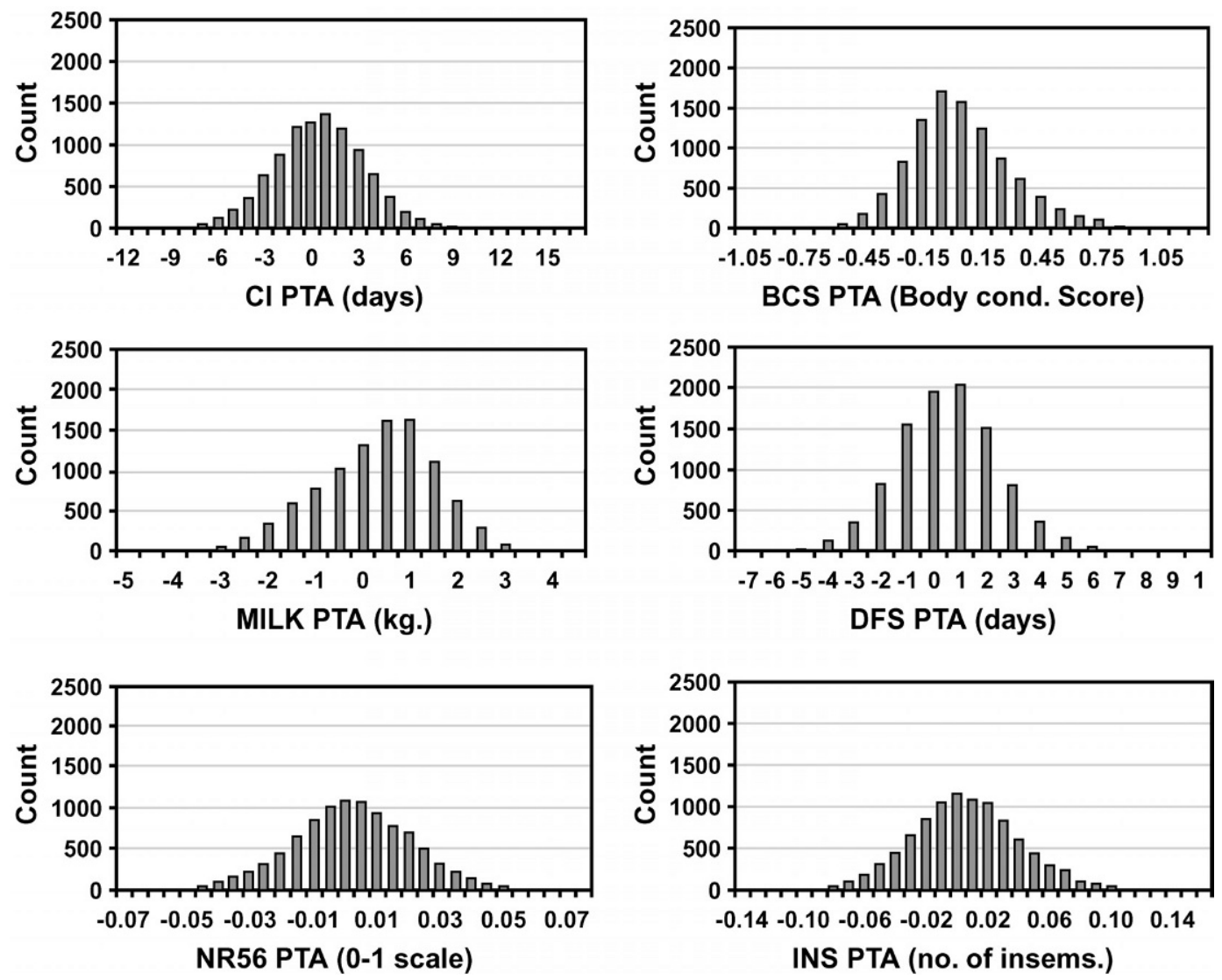

Figure 1. Distribution of sire PTA calving interval (CI), BCS, kilograms of milk at d 110 (MILK), days to first service (DFS), nonreturn rate (NR56), and the number of inseminations per conception (INS) for sires with at least 10 effective daughters in the analysis ( 10,000 sires). 

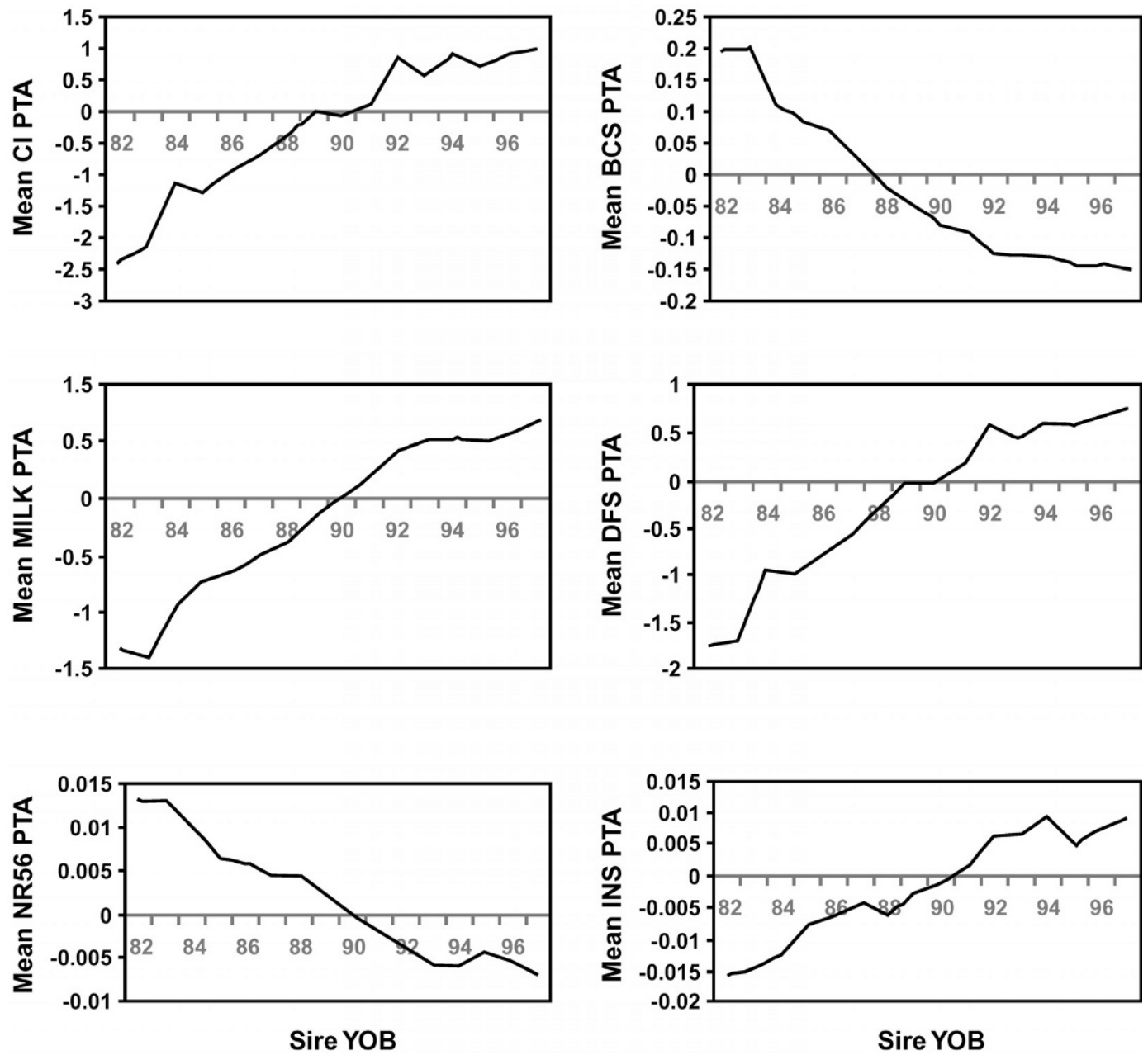

Figure 2. Genetic trends for calving interval (CI, days), condition score (BCS), kilograms of milk at d 110 (MILK), days to first service (DFS, days), nonreturn rate (NR56, 0/1), and the number of inseminations per conception (INS, count). YOB = year of birth.

in longer days to first service and calving intervals. There has been an increase in the number of inseminations per conception and an increase in the likelihood that an animal returns to service within $56 \mathrm{~d}$ (decrease in the NR56 trend). The genetic trends for the correlated traits show that MILK has been increasing, whereas BCS has been decreasing in recent years.

\section{Correlation of Fertility PTA with PTA for Other Traits}

The genetic correlations in Table 2 show that milk yield has an antagonistic relationship with fertility traits, and BCS has an unfavorable relationship with the fertility interval traits, suggesting thinner cows are likely to have longer calving intervals. Table 4 also shows that there are moderately unfavorable genetic correlations between production (MILK 305, FAT, and PROT) and associated indices (£PIN and £PLI) and each of the fertility traits (CI, DFS, NR56, INS), ranging from 0.25 to 0.67 . Previous studies have also shown an unfavorable relationship between health, longevity, and production traits (Dematawewa and Berger, 1998; Roman and Wilcox, 2000; Roxström and Strandberg, 2002). These unfavorable relationships suggest that selecting on production traits, or indices heavily influenced by production, will result in a decline in all aspects of fertility. There is very little difference between the correlations of the fertility traits with £PIN and $£$ PLI, suggesting that selection on these indices may cause a continued decline in fertility unless a direct measure of fertility information is included in the index. The correlation between LS and fertility is moderate, suggesting that improving longevity of animals will have a positive effect on fertility traits and vice versa. The correlations of the fertility traits with SCC were moderately low but favorable, suggesting that improv- 
Table 4. Approximate genetic correlations (correlations of PTA postadjustment by reliabilities) of the PTA for fertility and correlated traits with kilograms of milk, fat, and protein over a 305-d lactation, lifespan, SCC, and economic indices. ${ }^{1}$

\begin{tabular}{lcrrrrr}
\hline Trait & CI & DFS & NR56 & INS & BCS & MILK \\
\hline MILK 305 & 0.47 & 0.67 & -0.54 & 0.25 & -0.54 & 0.99 \\
FAT & 0.46 & 0.53 & -0.38 & 0.30 & -0.39 & 0.64 \\
PROT & 0.45 & 0.62 & -0.55 & 0.29 & -0.47 & 0.93 \\
£PIN & 0.46 & 0.58 & -0.49 & 0.31 & -0.43 & 0.81 \\
£PLI & 0.38 & 0.52 & -0.47 & 0.26 & -0.40 & 0.79 \\
LS & -0.51 & -0.45 & 0.23 & -0.30 & 0.29 & -0.31 \\
SCC & 0.13 & 0.12 & -0.09 & 0.09 & -0.15 & 0.27 \\
\hline
\end{tabular}

${ }^{1}$ MILK 305 = kilograms of milk over a 305-d lactation, FAT = kilograms of fat over a 305-d lactation, PROT = kilograms of protein over a 305-d lactation, £PLI = production and lifespan economic index, £PIN $=$ production only index, LS = lifespan PTA. For all other abbreviations, see Table 1.

ing SCC (i.e., reducing it) would result in a slight improvement in all aspects of fertility.

\section{DISCUSSION}

Heritability estimates of the fertility traits were low (2 to 5\%), whereas the correlated traits of BCS and MILK were moderately heritable. Heritabilities for fertility traits are known to be relatively low compared with those derived from physiological data, such as milk progesterone levels, because of the influence of management decisions (Pryce et al., 1997; Royal et al., 2002). Although the heritabilities were low, there was exploitable genetic variance in these traits as observed in variance component estimation and in PTA variance (Table 3 and Figure 2), which means that "good" fertility bulls can be distinguished from "bad." There had been an unfavorable decline in the breeding values of all fertility traits over recent years, with CI, DFS, and INS increasing, and NR56 decreasing (i.e., it is more likely that an animal will return to service). In the future, fertility indices may include endocrine (milk progesterone) data, perhaps recorded in automated parlors. As a means to monitor fertility, milk progesterone has an advantage in that it provides an indication of the physiological state of an animal, less obviously affected by management decisions on timing of inseminations and their conduct. The time to the onset of ovarian cyclicity postpartum (commencement of luteal activity), which can readily be identified from a rise in milk progesterone level (Royal et al., 2000), determines the earliest time at which a cow may be successfully inseminated, and is a useful measure of reproductive potential. Commencement of luteal activity has been shown to be favorably correlated with the more traditional measures of fertility, such as CI (Royal et al., 2002), and would help to both increase reliability and provide early proofs on test bulls.

There is a high correlation between the PTA for all traits in the analysis, and these correlations tended to be higher than the genetic correlations used in estimating the PTA. Ideally, the correlation between the PTA should be similar to the genetic correlations used to estimate them. If the correlation between PTA is significantly different from the genetic correlation, it is indicative of both differential reliability and the weight of information coming from the traits used to estimate the PTA of that trait. The genetic correlation, used for obtaining PTA, is the correlation between true breeding values and is akin to the correlation between PTA with very high reliabilities. As the reliability of the PTA drops, the correlation between them will be an underestimate of the magnitude of the genetic correlation. In a multitrait analysis, information on all traits is used to estimate the PTA of each trait. In this example, if there were no information on fertility, the correlation between the PTA would be expected to move away from the genetic correlation to +1 or -1 with yield, and hence be an overestimate of the genetic correlation. The genetic correlations between the direct measures of fertility and the correlations between the PTA for fertility traits are similar, but not the same. The correlations between the direct fertility measures and the correlated traits are generally slightly greater in magnitude than the genetic correlations (although distinct from +1 or -1 ), suggestive of their influence on the PTA. The most extreme difference can be seen in the genetic correlation between MILK and CI (0.27) and the correlation between the PTA of CI and MILK (0.48). The clear substantial movement away from + or -1 toward the genetic correlation indicates the much better discrimination made possible by the inclusion of BCS and insemination data.

There is a favorable genetic relationship between the traditional fertility traits, suggesting that improving 1 trait will have a favorable correlated response on them all. For example, decreasing CI by $10 \mathrm{~d}$ will reduce NR56 by $2.4 \%$. There is also a favorable relationship between lifespan PTA and the fertility PTA. However, the inclusion of LS with £PIN in £PLI made little differ- 
ence to the correlation of these indices with the fertility traits. This suggests that there will be little or no favorable indirect correlated response in fertility as a result of selection on £PLI. The correlation between the fertility traits and lifespan was moderately favorable and suggests that lifespan will increase by 0.27 of a lactation for a 10-d decrease in calving interval and 0.23 of a lactation for a $10 \%$ improvement in conception rate (therefore less inseminations). New index developments in the future may lead to the inclusion of fertility traits in the national economic index, and its use should lead to a reduction in the rate of decline of fertility traits in the United Kingdom. The approximate genetic correlation between SCC and the fertility traits was relatively low but suggested that decreasing CI by 10 $\mathrm{d}$ and improving conception rate by $10 \%$ would reduce SCC by 3.7 and $4.4 \%$, respectively. Future index development may lead to a multivariate analysis of these traits for inclusion in a multitrait index of production, health, longevity and fertility traits.

It is important to note the high and unfavorable correlation between BCS and production traits (e.g., MILK 305) in Table 4, indicating that sires with higher production proofs will tend to have daughters with lower body condition (Pryce et al., 2000). This lower condition at high yield levels will result in daughters being in greater negative energy balance and may lead to a reduction in fertility and health in these daughters, as seen by the correlation between BCS and fertility traits in Table 2. This negative energy balance has major management costs for fertility and health, as well as losses due to involuntary culling (Collard et al., 2000). The inclusion of BCS information or a direct measure of energy balance (Coffey et al., 2002) in a multitrait selection index with fertility, longevity, and production could help to improve the body energy status of cows.

The milk trait used as a correlated trait in this analysis was kilograms of milk at d 110, which is approximately the time of peak yield. This trait was chosen as the correlated milk yield trait as it is also approximately when cows become pregnant. Milk production PTA are based on 305-d (complete) lactation yields as opposed to a single point measurement during lactation. Brotherstone et al. (1997) estimated that the genetic correlation between LS (unadjusted) and first-lactation milk yield was 0.54 . This is expected to be an overestimate of the correlation between 305-d milk yield and functional (adjusted for within herd milk yield) LS, and simple calculations using the phenotypic linear regression on milk yield on unadjusted LS would suggest a value of 0.21 . The approximate genetic correlation between functional LS and milk at d 110 was -0.31 (Table 4). The correlation of -0.31 between $110-\mathrm{d}$ milk yield and LS implies that an increased peak milk yield is associ- ated with a decreased LS, whereas a high complete lactation yield results in increased functional LS. This indicates that persistent lactations with flatter curves may be associated with longer LS.

To address the continuing decline in fertility, health, and longevity, it is clear that breeding goals need to be broadened. However, optimized economic indices, which lead to the combination of traits to optimize profit, may not put enough weight on the nonproduction traits for any major improvement to be made in them. As the number of traits recorded increases, there is the potential for selection indices to be customized for different sectors of the dairy industry (e.g., organic farming vs. conventional farming). Future breeding objectives may be driven not only by the economics of selling milk, but by welfare, environmental issues, and consumer needs, which can have an implied economic impact on a production system. In this case, it may be necessary to move to a desired gains selection index to reflect unquantifiable consumer requirements.

\section{CONCLUSIONS}

Based on the results of this study, a fertility index for dairy cattle could include calving interval, BCS, milk yield at $110 \mathrm{~d}$, and a number of insemination traits. Nonreturn rate and the number of inseminations per conception are highly correlated with each other and would be useful in a genetic analysis because of the international compatibility of 56-d nonreturn rate and because inseminations per conception is accepted by farmers as a desirable goal trait. Including both conception traits and the 2 interval traits (CI and DFS) in a multivariate BLUP analysis will add to the reliability of the final proofs. The results show that there is wide genetic variation in the fertility traits, and therefore sufficient scope for selection.

\section{ACKNOWLEDGMENTS}

The authors would like to acknowledge the funding and support of the U.K. Department for Environment, Food and Rural Affairs, National Milk Records plc, Cattle Information Services (U.K.) Ltd., Genus Breeding Ltd., Cogent Breeding Ltd., Holstein U.K., and Dartington Cattle Breeding Trust through the LINK Sustainable Livestock Production Programme. We would also like to thank our research partners, T. Flint (University of Nottingham) and M. Royal (University of Liverpool) for their helpful suggestions and assistance throughout the project. The SAC receives financial support from the Scottish Executive Environment and Rural Affairs Department. 


\section{REFERENCES}

Berry, D. P., F. Buckley, P. Dillon, R. D. Evans, M. Rath, and R. F. Veerkamp. 2003. Genetic relationships among body condition score, body weight, milk yield and fertility in dairy cows. J. Dairy Sci. 86:2193-2204.

Brotherstone, S., G. Banos, and M. P. Coffey. 2002. Evaluation of yield traits for the development of an UK fertility index for dairy cattle. Proc. of the 7th World Cong. on Genetics Applied to Livest. Prod., Montpellier, France.

Brotherstone S., R. F. Veerkamp, and W. G. Hill. 1997. Genetic parameters for a simple predictor of the lifespan of Holstein-Friesian dairy cattle and its relationship to production. Anim. Sci. 63:31-37.

Calo, L. L., R. E. McDowell, L. D. VanVleck, and P. D. Miller. 1973. Genetic aspects of beef production among Holstein-Friesians pedigree selected for milk production. J. Anim. Sci. 37:676-682.

Coffey, M. P., G. Simm, and S. Brotherstone. 2002. Energy balance profiles for the first three lactations of dairy cows estimated using random regression. J. Dairy Sci. 85:2669-2678.

Collard, B. L., P. J. Boettcher, J. C. M. Dekkers, D. Petitclerc, and L. R. Schaeffer. 2000. Relationships between energy balance and health traits of dairy cattle in early lactation. J. Dairy Sci. 83:2683-2690

Dechow, C. D., G. W. Rogers, and J. S. Clay. 2001. Heritabilities and correlations among body condition scores, production traits, and reproductive performance. J. Dairy Sci. 84:266-275.

de Jong, G. 1997. Index for daughters fertility in the Netherlands. Proc. of the Int. Workshop on Genetic Improvement of Functional Traits in Cattle; Fertility and Reproduction, Grub, Germany. INTERBULL Bull. 18:102-105.

Dematawewa, C. M. B., and P. J. Berger. 1998. Genetic and phenotypic parameters for 305-day yield, fertility, and survival in Holsteins. J. Dairy Sci. 81:2700-2709.

Evans, R. D., F. Buckley, P. Dillon, and R. F. Veerkamp. 2002. Genetic parameters for production and fertility in spring-calving Irish dairy cattle. Ir. J. Agric. Food Res. 41:43-54.

Groen, A. F. 1999. Genetic Improvement of functional traits in cattle-Report from EU Concerted Action GIFT. Proc. of the 1999 INTERBULL Meeting Zurich, Switzerland. INTERBULL Bull. 22:115-120.

Groen, A. F., T. Steine, J.-J. Colleau, J. Pedersen, J. Pribyl, and N. Reinsch. 1997. Economic values in dairy cattle, with special reference to functional traits. Report of an EAAP-working group. Livest. Prod. Sci. 49:1-21.

Groeneveld, E., M. Kovac, and T. Wang. 1990. PEST, a general purpose BLUP package for multivariate prediction and estimation. Pages 488-491 in Proc. 4th World Cong. Genet. Appl. Livest. Prod. Edinburgh, Scotland.

Harrison, R. O., S. P. Ford, J. W. Young, and A. J. Conley. 1990. Increased milk production versus reproductive and energy status of high producing dairy cows. J. Dairy Sci. 73:2749-2758.

Hickman, C. G., A. J. Lee, and K. Gravir. 1969. Genotype × season $\times$ method interaction in evaluating dairy sires from progeny records. Can. J. Anim. Sci. 49:151-155.

Jones, H. E., I. M. S. White, and S. Brotherstone. 1999. Genetic evaluation of Holstein Friesian sires for daughter condition score changes using a random regression model. Anim. Sci. 68:467-476.

Kadarmideen, H. N., and M. P. Coffey. 2001. Quality and validation of insemination data for national genetic evaluations for dairy cow fertility in the United Kingdom. Proc of the INTERBULL Meeting, Budapest, Hungary. INTERBULL Bull. 27:133-138.

Kadarmideen, H. N., R. Thompson, and G. Simm. 2000. Linear and threshold genetic parameters for disease, fertility and milk production in dairy cattle. Anim. Sci. 71:411-419.

Mrode, R. A., G. J. T. Swanson, and M. S. Winters. 1998. Genetic parameters and evaluations for somatic cell counts and its relationship with production and type traits in some dairy breeds in the United Kingdom. Anim. Sci. 66:569-576.

Neumaier, A., and E. Groeneveld. 1998. Restricted maximum likelihood estimation of covariance in sparse linear model. Genet. Sel. Evol. 30:3-26.
Olori, V. E., T. H. E. Meuwissen, and R. F. Veerkamp. 2002. Calving interval and survival breeding values as measure of cow fertility in a pasture-based production system with seasonal calving. J. Dairy Sci. 85:689-696.

Pryce, J. E., M. P. Coffey, and S. Brotherstone. 2000. The genetic relationship between calving interval, body condition score and linear type and management traits in registered Holsteins. J. Dairy Sci. 83:2664-2671.

Pryce, J. E., R. J. Esslemont, R. Thompson, R. F. Veerkamp, M. A Kossaibati, and G. Simm. 1998. Estimation of genetic parameters using health, fertility and production data from a management recording system for dairy cattle. Anim. Sci. 66:577-584.

Pryce, J. E., G. Simm, and R. F. Veerkamp. 1997. Genetics of Fertility Traits. Society for the Study of Animal Breeding, Liverpool, U.K.

Pryce, J. E., and R. F. Veerkamp. 2001. The incorporation of fertility indices in genetic improvement programmes. Pages 223-236 in Fertility in the High-Producing Dairy Cow. M. G. Diskin, ed. British Society of Animal Science Occasional Publication No. 26. Edinburgh, Scotland.

Roman, R. M., and C. J. Wilcox. 2000. Bivariate animal model estimates of genetic, phenotypic and environmental correlations for production, reproduction, and somatic cells in Jerseys. J. Dairy Sci. 83:829-835.

Roxström, A., and E. Strandberg. 2002. Genetic analysis of functional, fertility-, mastitis-, and production-determined length of productive life in Swedish dairy cattle. Livest. Prod. Sci. 74:125-135.

Roxström, A., E. Strandberg, B. Berglund, U. Emanuelson, and J. Philipsson. 2001. Genetic and environmental correlations among the female fertility traits, and between the ability to show oestrus and milk production in dairy cattle. Acta Agric. Scand., Sect. A, Animal Sci. 51:192-199.

Royal, M. D., A. O. Darwash, A. P. F. Flint, R. Webb, J. A. Woolliams, and G. E. Lamming. 2000. Declining fertility in dairy cattle: Changes in traditional and endocrine parameters of fertility. Anim. Sci. 70:487-501.

Royal, M. D., A. P. F. Flint, and J. A. Woolliams. 2002. Genetic and phenotypic relationships among endocrine and traditional fertility traits and production traits in Holstein-Friesian dairy cows. J. Dairy Sci. 85:958-967.

Veerkamp, R. F., E. P. C. Koenen, and G. de Jong. 2001. Genetic correlations among body condition score, yield, and fertility in first-parity cows estimated by random regression models. J. Dairy Sci. 84:2327-2335.

Veerkamp, R. F., J. K. Oldenbroek, H. J. Van Der Gaast, and J. H. J. Van Der Werf. 2000. Genetic correlation between days until start of luteal activity and milk yield, energy balance, and live weights. J. Dairy Sci. 83:577-583.

\section{APPENDIX}

\section{Rules For Validating Insemination Information Traits}

Insemination records are voluntarily recorded and transcribed by milk recorders in the United Kingdom. A number of validation rules were required to assure the quality of the data, particularly nonreturn rate after $56 \mathrm{~d}$ (NR56), to overcome the inaccuracies in recording. The NR56 measures whether a cow returned to service within $56 \mathrm{~d}$ of its first service. If the cow is recorded as reinseminated within $56 \mathrm{~d}$ of its first recorded insemination, then it is recorded as a failure (coded as 0). If the cow does not have a second recorded insemination or its second insemination is greater than $56 \mathrm{~d}$ from its first recorded insemination, then it is recorded as a success (i.e., the cow did not return to service, coded as 1). 
The data were validated by predicting the date of successful insemination or the predicted date of pregnancy. Where possible, this date was back-predicted from the date of second calving by subtracting the gestation length $(280 \mathrm{~d})$. The insemination information was also validated using the date of last data extraction for that animal. With these 2 dates, a number of validation rules were tested and applied, which were:

1. If an animal's predicted insemination was $10 \mathrm{~d}$ or more before the first recorded insemination, the predicted insemination became the first and only insemination record. NR56 $=1$, the number of inseminations per conception (INS) $=1$, and days until first service (DFS) was recalculated.

2. If an animal's predicted insemination is more than $10 \mathrm{~d}$ after the first recorded insemination and more than $10 \mathrm{~d}$ before the second recorded insemination, the predicted insemination date becomes the second insemination record. NR56 recalculated, INS $=2$, and DFS unchanged.

3. If the predicted insemination occurred a long time after both the first and subsequent recorded insem- inations (300 d after first and so on) then the predicted insemination is the only insemination record used. NR56 $=1$, INS $=1$, and DFS recalculated.

4. If an animal's insemination records are recorded after the date of last data extraction, the insemination records are set to missing. NR56 missing, INS $=0$, and DFS $=0$.

5. If an animal has one insemination less than $86 \mathrm{~d}$ (56 d plus $30 \mathrm{~d}$ to allow for a recorder visit) from the date of last extraction, NR56 is set to missing. NR56 missing, INS = 1, and DFS unchanged.

6. If an animal has one insemination record, no calving interval, and less than $320 \mathrm{~d}$ to the last date recorded in the database ( $280 \mathrm{~d}$ for gestation, 1 estrus standard deviation, and $30 \mathrm{~d}$ recording visit leeway), then NR56 is interpreted as no return to service. NR56 $=1$, INS $=0$, and DFS unchanged.

7. If an animal has insemination information and no second calving but has had time to have a second calving, then she is given an unfavorable NR56 value. NR5 $=0$, INS $=0$, and DFS unchanged. 